\section{Os acertos de Descartes: implicações para a ciência, biomedicina e saúde coletiva}

\author{
Where Descartes got it right: the implications for \\ science, biomedicine, and public health
Los aciertos de Descartes: implicaciones para la ciencia, biomedicina y salud colectiva

André Luis de Oliveira Mendonça ${ }^{1}$ Kenneth Rochel de Camargo Jr. ${ }^{2}$

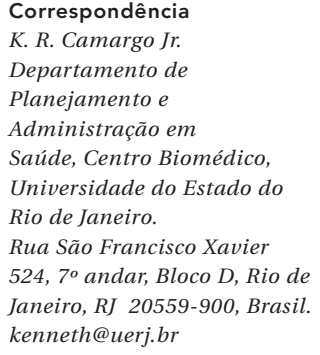

\begin{abstract}
A "visão recebida" acerca das ideias de Descartes contribuiu com a sedicalmente mente e corpo, tendo sido responsável, consequentemente, por ter fornecido os alicerces da "modernidade cindida". Não faltam epítetos, que tesiano: mecanicismo, determinismo, reducionismo, entre outros. Neste artigo nós desenvolvemos o argumento de acordo com o qual Descartes não foi um dualista do tipo como normalmente se supõe. Com base em uma releitura de duas das suas principais obras (Discurso do Método e Meditações Metafísicas) e de uma discussão com a nova literatura sobre o tema, sustenta-se a tese de que a superação da referida "visão recebida" pode produzir uma nova luz - nas discussões no/do campo da saúde coletiva - que pode dar relevo ao chamado paradigma ampliado da saúde (a valorização de outros aspectos que não apenas o biológico ou fisiológico, tais como o psicológico, social, econômico, cultural, político).
\end{abstract}

Filosofia Médica; Filosofia; Ciência; Saúde Pública 


\section{Introdução}

Há pouco mais de 20 anos, foi publicada uma das obras que ecoou e ajudou a fixar a imagem de Descartes como um dualista empedernido e símbolo-mor da "modernidade cindida", cujo título sintetiza as acusações costumeiras que lhe são feitas há tempos: O Erro de Descartes - escrita por António Damásio 1. O argumento principal do livro, desenvolvido em diálogo com as chamadas ciências do cérebro nas quais Damásio é um dos experts contributivos - para tomar emprestado a expressão de Collins \& Evans ${ }^{2}$-, consiste no pressuposto de que emoções e os sentimentos são elementos que desempenham um papel fundamental nas nossas decisões racionais; com a ressalva de que a ênfase nas emoções/sentimentos não levaria a um determinismo cultural (ou político) e de que o maquinário biológico e sociocultural das emoções seria bastante complexo, o que impossibilitaria um reducionismo simplório.

Supondo "existir um elo, em termos anatômicos e funcionais, entre razão e sentimentos, $e$ entre esses e o corpo" 1 (p. 276), Damásio visa à superação da velha e "nefasta" dicotomia entre corpo e mente, da qual Descartes seria um dos principais artífices. Além de ser apontado como um dos principais responsáveis pelos desdobramentos perniciosos da referida dicotomia, Descartes acaba sendo acusado de ter sido uma influência negativa quanto à negligência relativa do estudo científico do cérebro, em função de sua concepção "desencarnada da mente". Negligência essa que, por sua vez, teria engendrado duas consequências maléficas: (1) grande atraso nos estudos para se tentar entender a mente em termos biológicos; e (2) irremediável reducionismo quanto aos diagnósticos e tratamentos médicos. Objetivando a superação do "erro de Descartes" e de suas consequências, Damásio visa, por um lado, a alavancar e aprimorar os estudos da neurobiologia (tarefa em que ele vem se sagrando relativamente bem-sucedido nos últimos vinte anos), por outro, ampliar nossa concepção acerca dos problemas biomédicos (p.ex.: levar em conta tanto as consequências psicológicas das doenças do corpo quanto, inversamente, os efeitos dos conflitos psicológicos no corpo) 1 . Obviamente, a crítica erigida por Damásio contra o "cartesianismo" já foi feita, talvez até com mais consistência, no próprio interior das ciências humanas e sociais por diversos autores e vertentes. Toma-se sua obra aqui como exemplo paradigmático de uma concepção bastante difundida na literatura biomédica, por conta da qualidade e importância de seu trabalho.

Não constitui intuito dos autores deste artigo manter uma interlocução com Damásio, aqui, senão apenas usá-lo como mote desse ensaio, uma vez que ele é um autor emblemático daquilo que se denomina de "visão recebida" (interpretação hegemônica acerca do "dualismo" de Descartes, responsável por transformá-lo em uma espécie de espantalho); visão essa que, infelizmente, parece nortear os trabalhos daqueles que, como os autores deste artigo, são defensores de um paradigma ampliado da saúde - novo paradigma que precisa vir acompanhado das devidas ressalvas de que, seguindo Canguilhem, dessa saúde ampliada ninguém pode se dizer especialista ${ }^{3}$, e se todas as facetas do humano forem vistas como pertencentes à esfera da saúde, corre-se o risco de cair em uma extensão indefinida e indesejável do processo de medicalização da vida 4 . Da mesma forma, não se tencionou estabelecer uma reflexão demasiadamente técnica sobre o dualismo cartesiano, tampouco sobre o dualismo contemporâneo, o que obrigaria a debruçar sobre os tipos de dualismos, tais como, por exemplo, o numérico e o modal 5 . Neste artigo, atentou-se especificamente no segundo aspecto apontado por Damásio como uma infeliz decorrência do "erro de Descartes", a saber: o reducionismo biomédico ancorado no dualismo entre mente e corpo. Nesse sentido, o objetivo consiste em considerar as possíveis implicações das ideias formuladas por Descartes para o referido paradigma ampliado da saúde; aqui, desenvolve-se o argumento segundo o qual o pensamento cartesiano não deve ser visto como sinônimo de "mecanicista", "determinista" e "reducionista", dentre outros epítetos empregados de modo depreciativo, tal como costuma ser o caso em grande parte das menções desonrosas feitas ao "pai da modernidade" em alguns textos do campo da saúde coletiva. Para defender essa tese de modo convincente, realizaram-se dois movimentos sincronizados entre si: primeiramente, reconstruiu-se o pensamento epistemológico (metafísico) cartesiano, tal como ele está expresso e impresso na obra do próprio Descartes; em seguida, travou-se um diálogo com a literatura sobre a questão do suposto dualismo mente $\mathrm{x}$ corpo presente no pensamento de Descartes; por fim, foram extraídas algumas conclusões gerais, com ênfase nas questões concernentes ao campo da saúde coletiva.

\section{A ciência antes do descarte de Deus: Descartes por ele mesmo (por nós mesmos)}

Obviamente, a obra deixada por Descartes está inserida dentro de uma tradição heterogênea de pensamento (comumente denominada de racionalismo) que tem uma longa história, e continua 
viva ao menos no campo da filosofia. Mas, ao menos nessa seção, praticamente não se interagiu com tal tradição por uma atitude estratégica; para ser coerente com o convite à leitura da obra do próprio autor, procurou-se estabelecer um diálogo direto com Descartes, minimizando o recurso a de intérpretes, críticos ou mesmo comentadores. Interessa, neste primeiro momento, refletir sobre as bases epistemológicas do pensamento de Descartes, dada sua relevância - e até seu primado - para a árvore do saber que ele cultivou. Para tanto, foram (es)colhidas duas de suas principais obras: Discurso do Método e Meditações Metafísicas. Somente na sequência, deteve-se especificamente no problema da dicotomia mente $\mathrm{x}$ corpo, como se se estivesse, cartesianamente, partindo do geral para o particular.

Descartes costuma ser visto por muitos 6 como o fundador da filosofia moderna, ainda que isso seja controverso, já que, para outros autores, a modernidade filosófica propriamente dita tenha sido inaugurada por Kant e os idealistas alemães 7. Isso porque ele teria problematizado, pela primeira vez, a questão das fontes de validade e o alcance do conhecimento de modo explícito e relativamente sistemático, tendo como ponto de partida pensar o próprio pensamento - seria Descartes, como vaticinou Rorty, um criador de um "Olho Interno" ou "Olho da Mente" 8 ? Na interpretação crítica - histórica e conceitualmente embasada - de José Nodar, Descartes não foi o inventor da mente e nem mesmo foi um pensador essencialista, representacionista e fundacionista, tal como o rotulou negativamente Rorty 9. Seu pano de fundo histórico e alvo a ser atingido era, por um lado, o das intermináveis e "estéreis" disputas escolásticas - vivenciadas por ele desde sua formação na famosa instituição de ensino jesuíta College de La Flèche -, por outro, o dos ataques desferidos pelos céticos modernos em direção a esse mesmo mundo medieval, contra os quais Descartes formula uma espécie de trindade protetora: (1) provas racionais da existência de Deus e da imortalidade da alma; (2) fundamentação do saber na certeza autorreferenciada do sujeito; e (3) concepção de filosofia como investigação perene ${ }^{10}$. Se ainda não se encontrava o conhecimento verdadeiro é porque não se estava usando a razão corretamente. Descartes faz uma operação incomum até então, ao empregar a razão para refletir sobre a própria razão de modo a se poder descobrir qual sua natureza e seu alcance; assim, seria possível encontrar a melhor maneira de empregá-la. Se até aquele momento se buscara um fundamento seguro para o conhecimento na "realidade fora de nós" (Platão o teria "encontrado" no Mundo das Ideias; Aristóteles, na Substância; Tomás de Aquino, no Ser, entre tantos outros exemplos), Descartes teria inaugurado uma nova fase na história do pensamento em que a base do edifício do conhecimento deveria ser descoberta nos próprios homens, mais precisamente na razão.

Ao buscar um modo apropriado para utilizar a razão na busca pelo conhecimento certificado, Descartes está se referindo ao método como esse caminho apropriado para se alcançar uma meta (estando aqui, aliás, a própria explicitação da etimologia da palavra "método"). No Discurso do Método, após fazer uma avaliação crítica da formação que recebeu e do saber de sua época, ele propõe um retorno sobre si próprio ou sobre a própria razão. Apontando as insuficiências da lógica, da análise dos geômetras e da álgebra de seu tempo, ele propõe um novo método, visando a evitar o erro e assegurar a verdade, baseado em quatro regras: regra da evidência (só tomar como verdadeiro algo evidente por sua clareza e distinção); regra da análise (dividir as dificuldades surgidas em tantas partes quantas forem necessárias, de modo a resolvê-las melhor); regra da síntese (ir dos problemas mais simples para os mais complexos); regra da enumeração (empreender verificações gerais e completas, com o intuito de obter certeza de que todos os aspectos do problema foram respeitados). Regras essas que, vale lembrar, foram esmiuçadas em uma obra específica 11. No seu estilo literário confessional a la Agostinho, Descartes arremata:

"Mas o que me contentava mais nesse método era o fato de que, por ele, estava seguro de usar em tudo minha razão, se não perfeitamente, ao menos o melhor que eu pudesse; além disso, sentia, ao praticá-lo, que meu espírito se acostumava pouco a pouco a conceber mais nítida e distintamente seus objetos, e que, não o tendo submetido a qualquer matéria particular, prometia a mim mesmo aplicá-lo tão utilmente às dificuldades das outras ciências como o fizera com as da Álgebra. Não que, para tanto, ousasse empreender primeiramente $o$ exame de todas as que se me apresentassem, pois isso mesmo seria contrário à ordem que ele prescreve. Mas, tendo notado que os seus princípios deviam ser todos tomados à Filosofia, na qual não encontrava ainda quaisquer que fossem certos, pensei que seria mister, antes de tudo, procurar ali estabelecê-los; e que, sendo isso a coisa mais importante do mundo, e onde a precipitação e a prevenção eram mais de recear, não devia empreender sua realização antes de atingir uma idade bem mais madura do que a dos vinte e três anos que eu então contava e antes de ter despendido muito tempo em preparar-me para isso, tanto desenraizando de meu espírito todas as más opiniões que nele acolhera até essa época como acumulando muitas experiências, para servirem em seguida 
de matéria a meus raciocínios, e exercitando-me sempre no método que me prescrevera, a fim de me firmar nele cada vez mais" 12 (p. 40-1).

Entende-se, nessa passagem, que aparece de modo implícito uma das principais tensões na origem do pensamento moderno, qual seja: a busca incessante de um indivíduo particular por um método universal, necessário e atemporal, de sorte a servir de base a todo conhecimento pretensamente válido. Porém, a retórica dos modernos acerca da confiança e aposta no sujeito se dava, compreensivelmente, em virtude da necessidade que eles tinham de superar a tradição e a autoridade vigentes; sem contar o fato de o sujeito ser visto por eles como capaz justamente de anular os aspectos "subjetivos" do conhecimento. No caso de Descartes, na segunda parte do Discurso do Método, ele chega mesmo a criticar a concepção consensual de verdade e a rejeitar as opiniões alheias, os costumes (mesmo depois de relatar, com entusiasmo, as viagens que realizou para conhecer a cultura de outros lugares) e a herança cultural - ao menos como fontes seguras do conhecimento -, em nome da defesa da razão centrada no indivíduo. Voltar-se-á a essa temática um pouco mais à frente.

Descartes não queria somente encontrar a verdade por meio de um método seguro, senão também estar certo de que o conhecimento obtido era confiável. Nesse sentido, ele foi um dos primeiros a postular a certeza como condição da verdade. Isso que atualmente se classifica como uma tarefa epistemológica - pensar sobre as fontes do conhecimento validado ou justificado -, Descartes designou como uma "meditação metafísica”. Medite-se, ainda que sem a calma e o vagar típicos de seu tempo, sobre as suas Meditações.

Em sua procura apaixonada e até mesmo "mística" pela certeza como garantia da verdade (lembre-se do relato do sonho no qual teria recebido a "tarefa divina" de renovar o conhecimento de seu tempo), Descartes se vale, paradoxalmente, do método da dúvida. Não se trata de um duvidar real e autêntico, mas sim de uma estratégia em que se emprega a dúvida para colocar toda $\mathrm{e}$ qualquer verdade em xeque, com o fito de que se possa encontrar uma primeira certeza indubitável. Dessa forma, a dúvida funciona como um artifício metodológico hiperbólico; tanto assim que, após um primeiro momento desconstrutivo no qual todo o edifício do saber é implodido, há um segundo momento (re)construtivo em que tudo é reerguido, pedra por pedra.

O primeiro argumento desenvolvido por Descartes para duvidarmos do nosso conhecimento é o seu questionamento acerca da possibilidade de se conhecer as qualidades sensíveis dos ob- jetos singulares, posto que nossos sentidos com frequência nos induzem ao erro (e.g., ilusões de ótica)."Mas, ainda que os sentidos nos enganem às vezes, no que se refere às coisas pouco sensíveis e muito distantes, encontramos talvez muitas outras, das quais não se pode razoavelmente duvidar, embora as conhecêssemos por intermédio deles: por exemplo, que eu esteja aqui, sentado junto ao fogo, vestido com um chambre, tendo este papel entre as mãos e outras coisas desta natureza" 13 (p. 168). Logo em seguida, ele lança mão da hipótese do sonho, segundo a qual haveria possibilidade de tudo que acreditamos como real e verdadeiro não passar de um grande sonho, visto que, às vezes, nós confundimos o estado onírico com o estado de vigília (ao penetrar nos detalhes do argumento cartesiano, pode-se realmente acreditar estar sonhando, dado seu poder de persuasão).“...é preciso, todavia, confessar que há coisas ainda mais simples e mais universais, que são verdadeiras e existentes [os objetos da matemática, por exemplo]; de cuja mistura, nem mais nem menos do que da mistura de algumas cores verdadeiras, são formadas todas essas imagens das coisas que residem em nosso pensamento, quer verdadeiras e reais, quer fictícias e fantásticas" 13 (p. 169). Contudo, radicalizando no método da dúvida, Descartes recorre à hipótese do "gênio maligno", em que supõe a possibilidade de existir um Deus enganador que nos ludibria até mesmo acerca da forma de conhecimento aparentemente mais inquestionável, como o da matemática. Fique essa conjetura sem ser testada por ora.

Após a hipótese audaciosa do Deus que pode enganar, levando a se pensar ser verdade o que não passaria de ilusão, Descartes começa a refazer o edifício do saber pelo seu alicerce mais basilar, a saber, o cogito. Depois de perfazer todo o percurso da dúvida - do qual se fez acima uma reconstituição bastante sucinta, apresentando apenas a substância de seus argumentos e contra-argumentos, sem entrar nos seus meandros -, Descartes "conclui": se duvido, penso; penso, logo existo. Provavelmente, a sentença mais difundida da história da filosofia - e talvez a mais parodiada: desde "Sinto, logo existo" de Rousseau até o "Consumo, logo existo" de um anônimo -, "Penso, logo existo" condensa em si, para muitos, o espírito da modernidade e sua subsequente valorização do conhecimento racional. Aqui, quer-se tão somente chamar a atenção para o fato de os homens serem, para Descartes, primordialmente coisas pensantes; além disso, de terem acesso primeiramente ao pensamento e às ideias que o povoam. Mais importante ainda: há ideias contidas na mente que são inatas. Eis a inversão da maneira de pensar comum propiciada por Descartes: o verdadeiro conheci- 
mento não começa com - tampouco se fundamenta em - a experiência dos sentidos; ele, na verdade, origina-se nas ideias inatas (universais, necessárias e atemporais) do pensamento.

Entrando na lógica argumentativa de Descartes, há de se reconhecer a ousadia de sua cartada final (inicial): uma das ideias do espírito é a de Deus como um ser perfeito. Ora, a realidade objetiva de uma ideia clara e distinta de uma substância infinita só pode ser causada por uma realidade formal infinita que, portanto, é a própria substância infinita (reformulação do chamado argumento ontológico da existência de Deus, defendido por Anselmo e criticado por Tomás de Aquino) 14 . Só podendo a ideia de Deus ser oriunda do próprio Deus, não se teria mais necessidade de manter a hipótese do gênio maligno, uma vez que a ideia de um ser perfeito excluiria a possibilidade de ele ser um embusteiro perverso; um ser perfeito precisa ser necessariamente bom, já que a bondade seria um dos atributos da perfeição. "Provando" a existência do "bom Deus", Descartes poderá reconstruir todo o edifício do saber humano, que, agora, encontrou um fundamento absoluto e inabalável. Assim, logo na sequência, Descartes demonstrará a existência do mundo externo, que havia ficado em suspenso, como também da união do corpo e da alma, que ele também havia posto em questão. Meditando mais serenamente (ou tensamente?), Deus torna-se, para Descartes, o fundamento último do conhecimento ("científico") acerca das qualidades dos objetos externos. Note, entretanto, que o Deus do católico Descartes é aqui o Deus da razão e do pensamento: lembre-se de que a ideia de Deus é inata e, por conseguinte, seria independentemente do credo particular de cada um.

Na sexta e última parte das suas Meditações, Descartes procura pensar sobre a nova ciência emergente, da qual ele é um dos defensores e formuladores, além de explicitar as razões que o teriam levado a escrever o Discurso do Método. Sendo coerente com seu "pensamento meditativo", ele preconiza o emprego do método dedutivo para a ciência (dos princípios e primeiras causas para os efeitos particulares). No entanto, justiça seja feita, Descartes não deixa de reconhecer, ao contrário do que costumam afirmar, a importância das "experiências científicas"; o que ele questiona é a viabilidade concreta delas no seu caso particular, no sentido de ele ter ou não condições físicas e materiais para realizá-las. Ora, eis aqui mais um exemplo da tensão originária dos modernos: por que haveria necessidade de ele mesmo levar a cabo certas experiências, em vez de confiar no "testemunho" das de outrem? O paradoxo entre o individual e o universal chega ao extremo quando Descartes conclui que as experiências devem ser tornadas públicas. A passagem transcrita a seguir revela todo esse drama:

“...mas vejo também que são tais [as experiências] e em tão grande número que nem minhas mãos, nem a minha renda, ainda que eu tivesse mil vezes mais do que tenho, bastariam para todas; de sorte que, conforme tiver doravante a comodidade de fazê-las em maior ou menor número, avançarei mais ou menos no conhecimento da natureza. Fato que prometia a mim próprio tornar conhecido, pelo trabalho que escrevera, $e$ mostrar tão claramente a utilidade que daí poderia advir ao público que obrigaria a todos os que desejam em geral o bem dos homens, isto é, todos os que são de fato virtuosos, e não apenas por fingimento, nem somente por opinião, tanto a comunicar-me as que já tivessem feito como a me ajudar na pesquisa das que restam por fazer" 13 (p. 65).

Do exposto, pode-se inferir que a epistemologia (ou metafísica) cartesiana "encontra" na ideia (inata) de Deus, contida no cogito, a "pedra filosofal" sobre a qual o edifício do conhecimento poderá ser construído com absoluta segurança, sem risco de desabamento. Seria Descartes um moderno legítimo, ao ainda ter buscado a garantia de certeza acerca da verdade científica em Deus? Poder-se-ia responder que, malgrado todo o atual ataque ao "cartesianismo frio, dicotômico, reducionista etc.”, Descartes continua algures sendo considerado um dos fundadores da modernidade - dentre outros motivos, por sua ênfase na razão e no pensamento; seja como for, não se pode esquecer que, além de Meditações Metafísicas, ele escreveu um livro chamado As Paixões da Alma, dentre outras obras que tornam pouco crível a imagem de Descartes sustentada por Damásio e vários outros autores. Sem contar que é também na Meditação Sexta, além de excertos de outras obras, que Descartes defende, com clareza e distinção, a tese da diferenciação e, ao mesmo tempo, união entre corpo e alma. Mas, deixe-se para discutir esse tópico em diálogo, agora sim, com a literatura revisionista acerca do seu suposto dualismo.

\section{Reexame do Dr. Descartes: o duelo do dualismo}

Obviamente, a visão acerca do pensamento cartesiano delineada acima deve ficar circunscrita às duas obras analisadas aqui, pois, ao contrário daquilo que pressupõem as interpretações hegemônicas no interior da história da filosofia, as ideias formuladas por Descartes mudaram com o tempo, sobretudo em função do affair Galileu ${ }^{15}$. Não obstante, independentemente dessas 
mudanças, pode-se dizer - embora um pouco anacronicamente - que os trabalhos científicos realizados por Descartes estavam ancorados em um pensamento epistemológico (ou metafísico) coerente e consistentemente argumentado. Diz-se "anacronicamente" porque acredita-se piamente que Descartes não estabelecia uma distinção clara entre filosofia (epistemologia) e ciência. Em que pesem suas contribuições para a matemática e a física, contudo, no âmbito biomédico sua relevância talvez seja reconhecida como filósofo ou epistemólogo, não como cientista, palavra que, aliás, só será cunhada por William Whewell no século XIX. Fuller 16 defende a ideia controversa e ao mesmo tempo interessante, de acordo com a qual seria tão somente retrospectivamente que os cientistas costumam rotular de "filósofos" os perdedores de uma controvérsia e de "cientistas" os vencedores. E, de fato, Descartes "perdeu" muitas querelas científicas. Será que ele "ganhou" na biomedicina, campo em que ele teria sido justamente mais equivocado consoante a visão retrospectiva prevalecente hoje? Nesta seção, será feito um breve resumo das ideias cartesianas referentes à medicina em diálogo com alguns trabalhos recentes que concorrem na contramão das concepções tais como a propalada por Damásio.

Para aqueles apenas acostumados com ou “iniciados" no seu "pensamento filosófico", pode não soar muito trivial a associação de Descartes com a medicina, especialmente com o pressuposto de que ele teria deixado uma marca indelével na criação do chamado método anátomo-clínico. Não obstante as esparsas discussões acerca do seu "pensamento médico" no interior da história da filosofia, o fato é que Descartes se ocupou com a ciência médica em muitas ocasiões, até porque - faz-se oportuno enfatizar - o objetivo-mor do seu "novo método", explicitado no último parágrafo do Discurso do Método, consistia em renovar a medicina de seu tempo: "mas direi unicamente que resolvi não empregar o tempo de vida que me resta em outra coisa exceto procurar adquirir algum conhecimento da natureza, que seja de tal ordem que dele se possam tirar regras para a medicina, mais seguras do que as adotadas até agora" 12 (p. 71).

Em La Philosophie Médicale de Descartes 17, Vincent Aucante pretende justamente preencher essa lacuna na história da filosofia: a ciência médica é repensada por Aucante como um objetivo integral do sistema filosófico cartesiano. Nessa obra já considerada notável sobre o tema, além de discorrer sobre seu conhecimento fisiológico (duas matérias são destacadas: geração e desenvolvimento fetal/manifestação da dor na mente), o autor martela a imagem mítica do Descartes dualista: o objeto da medicina para Descartes é o homem integral (união mente e corpo); sem contar a assertiva de que a medicina cartesiana precisa ser repensada em congruência com seu projeto de conhecimento unificado (árvore da filosofia) 17,18 .

Com o sugestivo título Descartes the Doctor: Rationalism and Its Therapies 19, o historiador da ciência Steve Shapin também desenvolve o argumento de acordo com o qual o objetivo central do programa cartesiano de reforma filosófica localizava-se na busca incessante por uma profilaxia médica e terapêutica capazes de estender a vida humana. Manuseando a correspondência entre Descartes e seus colegas médicos, Shapin constata que ele manifestou o interesse em ser seu próprio médico, defendendo o ideal de autonomia do indivíduo ${ }^{19}$. Interação essa que foi particularmente frutífera com os médicos holandeses, no período em que viveu em Amsterdã 20. Segundo Shapin, Descartes fez prescrições para amigos e colegas, recorrendo a uma dietética temperada ou moderada: alimentação adequada, estilo de vida, formas de exercício, padrões de sono, modos de expressão e contenção emocional, bem como tipos de estimulação intelectual, levando em conta a condição específica de cada um. Deixando de lado o conteúdo de cada um dos itens dessa lista e se detendo nas recomendações "em si mesmas", fica difícil não identificar em Descartes um pensador próximo do paradigma ampliado da saúde contemporâneo, ou melhor, ele pode servir como uma espécie de inspirador desse projeto, ao invés de ser visto como um adversário.

Mais importante ainda foi a centralidade da noção de "cheer up" no seu pensamento médico: o reconhecimento da influência da alma (mente) sobre o corpo (psicossomático ou somato-psíquico). Na interpretação de Shapin, Descartes defendeu uma espécie de interacionismo entre mente e corpo, tendo chamado a atenção para a necessidade de um "administrar volitivo" das paixões em função da sua incidência no nosso estado de saúde. E mais: Descartes reconheceu o status híbrido da medicina (corpo em geral como objeto da ciência médica e corpo particular como objeto da arte médica). Não bastasse esse tipo de vanguardismo, ele também estava cônscio de a arte (prática) médica ser pautada pela incerteza; sendo os melhores guias, em situações de dúvida, o costume e o senso-comum ${ }^{19}$. São essas contribuições mais - por que não dizer? humanísticas atinentes à medicina que deveriam fazer parte do legado cartesiano, e não a do suposto dualismo radical, tampouco da imaginária criação do "frio" método anátomo-clínico; sendo a influência de Descartes quanto ao surgimento 
do referido método, se é que ela houve, meramente indireta 21.

Inspirado pelo mesmo espírito - presente na reflexão deste artigo - de atentar para a letra do pensamento de Descartes, Grant Duncan redigiu um artigo incontornável para todos aqueles que querem sinceramente conhecer Descartes por ele mesmo, e não pelas distorções até mesmo vulgares das quais ele é vítima. Em um trabalho de grande erudição, Duncan disserta sobre duas teses centrais acerca do suposto "dualismo cartesiano" em sua relação com a teoria contemporânea biopsicossocial sobre a dor: (1) o binômio mente-corpo diz respeito a entidades diferentes, porém unificadas (efeito da mente sobre o corpo); (2) como uma espécie de corolário da primeira tese, o chamado dualismo cartesiano é aproximado do modelo biopsicossocial da dor e distanciado das teorias mecanicistas. A dor é vista por Descartes como prova da existência do corpo e também como evidência da conjunção entre mente e corpo (substâncias distintas, mas unificadas). O ponto falho nevrálgico em Descartes residiria não na falta de interseção em si, mas sim na ausência de discussão acerca da natureza da relação de interação propriamente dita entre corpo e mente. Ela seria devido à causação ou à intervenção divina? Após questionar essa e outras deficiências do pensamento cartesiano, como também depois de reconstruir, criticamente, as principais teses dos adeptos do modelo biopsicossocial, Duncan acusa-os de também não terem equacionado satisfatoriamente o problema da natureza da interação entre mente e corpo, recaindo, assim, em uma espécie de dualismo. Quanto ao suposto dualismo cartesiano especificamente, o autor conclui que ele é apenas parte de uma cisão muito mais ampla da filosofia, da história e da cultura 22 . Não se pode esquecer também de que o tipo de dualismo cartesiano era uma forma estratégica, por assim dizer, de servir a dois senhores: ciência (corpo) e religião (alma).

\section{Conclusão: além do "bem" (holismo) e do "mal" (reducionismo)}

É claro que se está cônscio de que as críticas dirigidas a Descartes atualmente são muito mais motivadas em razão do suposto espírito cartesiano que rondaria ainda os muros da academia do que contra a letra dos seus próprios textos. Porém, não obstante o reconhecimento de o espírito dualista não ser um mero fantasma, senão mentalidade e prática ainda hegemônicas, não se pode perder de vista o registro histórico: o próprio Descartes não foi, por assim dizer, um “cartesiano". Não bastasse o compromisso que os pesquisadores devem ter com a verdade como um fim em si mesmo, ao recuperar o pensamento de Descartes em seus próprios termos, pode-se ser agraciado com todo um arsenal teórico que pode auxiliar a dar conta dos problemas do tempo atual. Sejam tiradas algumas pequenas conclusões positivas para as discussões sobre ciência, bem como para as abordagens acerca da biomedicina levadas a termo no campo da saúde coletiva. Com a ressalva de que os "acertos" de Descartes não podem ser aqui tomados como certezas absolutas; afinal, tanto em filosofia quanto em ciência, sem querer fazer um mero jogo de palavras, a única coisa certa é a de que se é sempre passível de erro.

Talvez a grande contribuição de Descartes, tal como a primeira seção deste ensaio permite inferir, reside na relevância que ele atribui à reflexão filosófica para a prática científica e médica. A rigor, em Descartes, esses saberes ainda não eram concebidos como completamente separados ou autônomos. Nele, as discussões acerca de fundamento são, de fato, fundamentais para se produzir conhecimento válido e confiável; ou seja, sem filosofia a ciência corre sério risco de desmoronar, ou mais ainda, a reflexão filosófica fornece sentido, em sentido amplo, à prática científica. Outro legado importante de Descartes pode ser extraído das reconsiderações formuladas por autores como Steven Shapin, na medida em que permitem repensar o imaginário social acerca da ciência (mecanicismo, determinismo, reducionismo etc.) sob nova luz, desreificando-o: a ciência moderna não é una e homogênea; várias foram suas concepções de natureza, de método, de conhecimento etc. Ou seja, por que não dizer, o pensamento cartesiano, aggiornado com bases mais historicistas e construtivistas, pode funcionar como um antídoto contra o pós-modernismo que envenena partes consideráveis da academia e da sociedade.

Por fim, mas não menos importante, acredita-se aqui que a superação da vulgata em torno da figura de Descartes pode ser liberadora para aqueles que, na saúde coletiva, debruçam-se sobre formas contra-hegemônicas de se pensar a clínica e a assistência em geral. O chamado paradigma ampliado, que é tão relevante no processo de elaboração de novos modos de se conceber a biomedicina e as ciências da saúde, atentando-se para seus múltiplos fatores interligados, pode passar a ter suas discussões reaquecidas e aprofundadas com o recrutamento de um aliado peso-pesado. O Descartes de carne e osso é, a um só tempo, mais complexo e mais interessante do que o "verdadeiro pai da modernidade" dos cartesianos recalcitrantes e do que o "pai das mazelas da modernidade" dos anticartesianos 
apressados. Sem contar que, assim como não foi um reducionista de mente tacanha, Descartes pode ajudar a pensar a integralidade sem que seja necessário recorrer à ideia de holismo; afinal, corpo e alma (mente) estão interconectados,

\section{Colaboradores}

Ambos os autores participaram da concepção intelectual, revisão bibliográfica e redação do texto. mas não são uma única e mesma substância. Portanto, dai à ciência o que for da ciência; dai a outros saberes o que for de outros saberes - ou dai às diferentes ciências os problemas que são capazes de resolver.

\section{Agradecimentos}

A Marcos Gleizer pela inspiradora palestra O Projeto Cartesiano de Fundamentação da Ciência e o Problema Mente-Corpo, ministrada no Instituto de Medicina Social da Universidade do Estado do Rio de Janeiro (UERJ), em 2013. A Antonio Videira, Leandro Gonçalves, Mônica Corrêa e Thompson Lemos pela leitura generosa e pelo encorajamento quanto à submissão do texto para publicação e a Alden Neves pelas conversas sobre Descartes. Ao Conselho Nacional de Desenvolvimento Científico e Tecnológico (CNPq), Fundação de Amparo à Pesquisa do Estado do Rio de Janeiro (FAPERJ) e UERJ, pelo financiamento.

\section{Referências}

1. Damásio A. O erro de Descartes: emoção, razão e o cérebro humano. São Paulo: Companhia das Letras; 1996.

2. Collins H, Evans R. Repensando a expertise. Belo Horizonte: Fabrefactum; 2010.

3. Canguilhem G. Écrits sur la médecine. Paris: Seuil; 2002.

4. Camargo Jr. KR. As armadilhas da "Concepção Positiva de Saúde”. Physis (Rio J.) 2007; 17:63-76.

5. Wee C, Pelczar M. Descartes' dualism and contemporary dualism. South J Philos 2008; XLVI:145-60.

6. Arendt H. A condição humana. Rio de Janeiro: Forense-Universitária; 1981.

7. Habermas J. O discurso filosófico da modernidade. Lisboa: Publicações Dom Quixote; 1990.

8. Rorty R. Philosophy and the mirror of nature. Princeton: Princeton University Press; 1979.

9. Nodar J. El inventor de la mente? Una crítica a la lectura rortiana de Descartes. Signos Filosóficos 2010; XII:69-98.

10. Bahr F. Los escépticos modernos y la génesis del cogito cartesiano. Revista Latinoamericana de Filosofía 2010; XXXVI:59-85.

11. Descartes R. Regras para a orientação do espírito. 3a Ed. São Paulo: Martins Fontes; 2012.

12. Descartes R. Discurso do método. In: Descartes R. Discurso do método; As paixões da alma; Meditações metafísicas. 5a Ed. São Paulo: Nova Cultural; 1991. (Coleção Os Pensadores). p. 25-71.
13. Descartes R. Meditações metafísicas. In: Descartes R. Discurso do método; As paixões da alma; Meditações metafísicas. 5a Ed. São Paulo: Nova Cultural; 1991. (Coleção Os Pensadores). p. 165-224.

14. Gilson E. A filosofia na Idade Média. São Paulo: Martins Fontes; 2001.

15. Machamer P, McGuire J. Descartes's changing mind. Stud Hist Philos Sci 2006; 37:398-419.

16. Fuller S. Kuhn vs Popper: the struggle for the soul of science. Cambridge: Icon; 2003.

17. Aucante V. La philosophie médicale de Descartes. Paris: Presses Universitaires de France; 2006.

18. Manning G. Out of limb: the place of medicine in Descartes's philosophy. Early Sci Med 2007; 12:214-22.

19. Shapin S. Descartes the doctor: rationalism and its therapies. Br J Hist Sci 2000; 33:131-54.

20. Donatelli M. Descartes e os médicos. Scientiae Studia 2003; 1:323-36.

21. González Hernández A, Domínguez Rodríguez MV, Fabre Pi O, Cubero González A. Descartes' influence on the development of the anatomoclinical method. Neurología 2010; 25:374-7.

22. Duncan G. Mind-body dualism and the biopsychosocial model of pain: what did Descartes really say? J Med Philos 2000; 25:485-513. 


\section{Abstract}

The "received view" of Descartes has shaped the image of a dualist thinker who radically separated mind and body and thus laid the foundations for a "divided modernity". Numerous epithets have been applied to Cartesian thinking, all of which now sound depreciative mechanicism, determinism, and reductionism, among others. This article contends that Descartes was not the type of dualist that is normally assumed. Based on a rereading of two essential works (Discourse on Method and Metaphysical Meditations) and a dialogue with the new literature on the theme, we contend that overcoming the "received view" of Descartes can shed new light on discussions in (and of) the collective health field and highlight the so-called expanded health paradigm (including aspects beyond the biological or physiological, such as the psychological, social, economic, cultural, and political).

Medical Philosophy; Philosophy; Science; Public Health

\section{Reumen}

La "visión recibida" de las ideas de Descartes contribuyó a la sedimentación de la imagen de un pensador dualista, que habría separado radicalmente mente y cuerpo, siendo responsable, consecuentemente, de haber proporcionado los fundamentos de la considerada "modernidad escindida". No faltan epítetos, que actualmente suenan en cierta medida despreciativos, para referirse al pensamiento cartesiano: mecanicismo, determinismo, reduccionismo, entre otros. En este artículo desarrollamos el argumento, de acuerdo con el cual, Descartes no fue un dualista del tipo que normalmente se le supone. En base a una relectura de dos de sus principales obras (Discurso del método y Meditaciones Metafísicas), y de una discusión con la nueva literatura sobre el tema, se sostiene la tesis de que la superación de la referida "visión recibida" puede producir una nueva luz -en las discusiones en el/del campo de la salud colectiva- que puede dar relevo al llamado paradigma ampliado de la salud (la valorización de otros aspectos, no solamente el biológico o fisiológico, tales como el psicológico, social, económico, cultural, político).

Filosofía Médica; Filosofía; Ciencia; Salud Pública

Recebido em 24/Set/2015

Versão final reapresentada em 26/Jan/2016

Aprovado em 25/Fev/2016 